FIRTH : SOME FACTORS GOVERNING THE

\title{
CIII.--Some Factors Governing the Sorptive Capacity of Charcoal. Sorption of Ammonia by Cocoa-nut Charcoal.
}

By James Brierley Firth.

IN a previous paper (Firth, Zeitsch. physikal. Chem., 1914, 86, 307), the author pointed out the great difference in activity of the cocoanut charcoals used by various experimenters, even although the methods of preparation and treatment were very similar. Thus, in the case of the sorption of hydrogen at liquid-air temperatures, Travers (Proc. Roy. Soc., 1906, 78, 9) obtained the values 7.3 c.c. at $12 \mathrm{~mm}$. and 16.7 c.c. at $248 \mathrm{~mm}$.; McBain (Phil. Mag., 1909, [vi], 18, 916), 23.5 c.c. at $10 \mathrm{~mm}$.; Firth (loc. cit.), 30 c.c. at $12 \mathrm{~mm}$. and $78 \mathrm{c}$ c.c. at $241 \mathrm{~mm}$. per gram of charcoal in each case.

This wide difference in activity of the charcoals required further investigation, and it was with the object of determining some of the factors which govern the activity that the present investigation was undertaken.

The earlier belief was that the most active charcoal was obtained by carbonising at as low a temperature as possible with the minimum amount of heating. Hunter (Phil. Mag., 1863, [iv], 25, 365) observed that different samples of similarly prepared charcoals had different activities, which he explains thus : "The variations in the amount of absorption are probably due in part to the slight differences which must exist in the pores of different pieces of the same charcoal and also to unavoidable differences in the heating of the charcoals in each experiment.

"In order to determine the effect of long-continued heat on the absorbing power of the charcoal I kept a piece of boxwood charcoal at a strong red heat for upwards of an hour, after which its absorption for ammonia was found to be 79 , while in the ordinary way it was 85. ." 
Travers (loc. cit.) states that "if the charcoal has been too strongly heated, it loses its power of absorbing colouring matters and, indeed, substances generally either in the gaseous state or in solution, and this may be explained by the fact that the action of heat results either in the partial conversion of the carbon into a more stable crystalline phase, into which substances diffuse less readily, or in causing it to become more compact, in which case the surface is limited and each 'diffusion column ' becomes longer." If this statement is correct, it will be highly probable that such a partial conversion will involve a change in the density of the charcoal, and one may reasonably look for a continuous change in activity with change in density. Hence the first experiments had for their object the determination of the relation (if any) between the temperature at which the charcoal had been heated, the dura. tion of heating, the change in density, and the activity.

Winter and Baker (T., 1920, 117, 320) have shown that, in the case of sugar-carbon which has been heated for forty hours at $900^{\circ}$, the density increases from $1 \cdot 76-1 \cdot 84$, and by the same treatment the amount of sulphur dioxide "absorbed" increases from 97 c.c. to 288 c.c.

The charcoal used in the present investigation was obtained from cocoa-nut shell. The gas chosen was ammonia, since it can readily be obtained pure, and the amount sorbed is considerable. Saussure (Ann. Physik [Gilbert], 1814, 47, 112) found that beechwood charcoal sorbed ninety times its volume of ammonia at $12^{\circ}$ and $724 \mathrm{~mm}$. Hunter (Phil. Mag., 1865, [iv], 29, 116) found that cocoa-nut-shell charcoal sorbed 171.7 volumes of ammonia at $0^{\circ}$ and $760 \mathrm{~mm}$.

\section{EX P E R I E N T A L.}

The essential part of the apparatus was the same as that already described in the case of the sorption of hydrogen (Firth, loc. cit.).

The carbon was prepared by carbonising cocoa-nut shell at as low a temperature as possible. The carbon obtained was exceed. ingly hard and dense and difficult to powder, and gave 0.91 per cent. of ash. It was then digested several times with hot, concentrated hydrochloric acid, boiled with distilled water, and washed free from chloride. The percentage of ash was now 0.39 , and further treatment of the eharcoal did not appreciably reduce this value. The carbon was then finely powdered and sieved. The ammonia was prepared from concentrated ammonia solution. The gas was passed through a hard glass tube, oontaining lime at a red heat, into pure hydrochloric acid, whereby pure ammonium chloride was obtained, This was heated with a solution of sodium 
hydroxide and the resulting ammonia passed through large towers, containing calcium oxide and solid potassium hydroxide, into a large bulb, which served as a reservoir. Measurements were made at three temperatures, $18^{\circ}, 0^{\circ}$, and $-20^{\circ}$. The temperature $-20^{\circ}$ was obtained by stirring solid carbon dioxide into a bath of alcohol contained in a vacuum vessel, this being further protected by surrounding it with a box packed with cotton-wool. Solid carbon dioxide was added in small quantities from time to time.

The charcoal was heated at different temperatures for various periods. After each heating, the density was determined and then the sorptive capacity at each of the three temperatures, $18^{\circ}, 0^{\circ}$, and $-20^{\circ}$. The temperature at which the charcoal was heated was approximately determined by means of a pyrometer.

No matter what the previous treatment of the charcoal may have been, when transferred to the sorption apparatus it was invariably heated at a dull red heat in a vacuum for two hours, allowed to cool to the temperature of the bath, and then ammonia admitted.

At $0^{\circ}$ and at $-20^{\circ}$, the sorption was very rapid during the first few minutes, whereas at $18^{\circ}$, after the initial exposure, the sorption was more gradual. In all cases the sorption became extremely slow after the first hour, being complete in about thirty-six hours.

The volumes given refer to one gram of the charcoal in each case and are corrected to N.T.P.

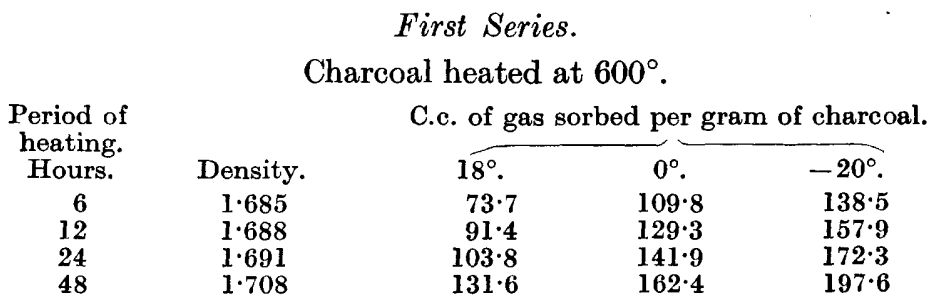

It is evident from these experiments that continued heating has considerably increased the activity of the charcoal, whilst the density has been slightly increased.

Second Series.

Charcoal heated at about $875-900^{\circ}$.

\begin{tabular}{ccccc}
$\begin{array}{c}\text { Period of } \\
\text { heating. }\end{array}$ & \multicolumn{3}{c}{ C.c. of gas sorbed per gram of charcoal. } \\
Hours. & Density. & $18^{\circ}$. & $0^{\circ}$. & $-20^{\circ}$. \\
6 & $1 \cdot 712$ & $143 \cdot 8$ & $188 \cdot 4$ & $221 \cdot 7$ \\
12 & $1 \cdot 752$ & $173 \cdot 8$ & $223 \cdot 6$ & $269 \cdot 8$ \\
24 & $1 \cdot 801$ & $203 \cdot 1$ & $256 \cdot 3$ & $298 \cdot 4$ \\
48 & $1 \cdot 825$ & $211 \cdot 7$ & $268 \cdot 3$ & $317 \cdot 8$
\end{tabular}


Heating at $900^{\circ}$ has produced a further increase in sorptive capacity, and at the same time the density has been appreciably increased.

A portion of the charcoal which had been heated at $900^{\circ}$ for forty-eight hours and had D 1.825 was set aside for three months in a stoppered bottle, after which period its sorptive capacity was redetermined (it was heated at $600^{\circ}$ in a vacuum for two hours before exposure to ammonia, as in previous experiments), with the following results :

$$
18^{\circ}, 185 \cdot 5 \text { c.c.; } 0^{\circ}, 254 \cdot 2 \text { c.c. } ;-20^{\circ}, 303 \cdot 1 \text { c.c. }
$$

A quantity of charcoal was heated at $875-900^{\circ}$ for seven days, with the result that the density increased to $1 \cdot 985$, and the sorption values were :

$$
18^{\circ}, 193 \cdot 2 \text { c.c. } ; 0^{\circ}, 249 \cdot 6 \text { c.c. } ;-20^{\circ}, 302 \cdot 1 \text { c.c. }
$$

\section{Third Series.}

Charcoal heated at about $1050^{\circ}$.

$\begin{array}{cc}\begin{array}{c}\text { Period of } \\ \text { heating. }\end{array} & \\ \text { Hours. } & \text { Density. } \\ 3 & 1 \cdot 782 \\ 12 & 1 \cdot 914 \\ 24 & 2 \cdot 116\end{array}$

C.c. of gas sorbed per gram of charcoal.

The experiments show that charcoal can be considerably activated by prolonged heating. At $600^{\circ}$, a considerable increase in the amount of gas sorbed is obtained without a very great change in the density. At $900^{\circ}$, a much greater increase is obtained, which is coincident with an appreciable increase of density. Further experiments show that increase of density does not necessarily mean increased activity. It would appear from the results that prolonged heating at $900^{\circ}$, or heating at higher temperatures, tends to convert the carbon into a denser form with diminished sorptive capacity, and that the observed density is merely an average value dependent on the proportion of each form. Hence increase of density may result in diminished activity. Further, when the charcoal is rapidly brought to a high temperature (above $1000^{\circ}$ ), a portion of the carbon may be converted into the denser form, whilst the bulk of the carbon has not materially changed. In this case the density may coincide with that of a carbon which has been heated, not so strongly, but for a longer period; yet the two forms would have very different sorptive capacities (compare series II and III). Hence density cannot be regarded as the criterion of activity. 
It would appear also from the results that the activity of the carbon deteriorates with time. The results in general show that it is necessary to know the history of a charcoal, and a record of the density of the carbons used would make the results obtained by various experimenters more comparable, particularly in cases where the carbon has not been too strongly heated and consequently the formation or presence of the denser carbon is not very probable.

Fig. 1.

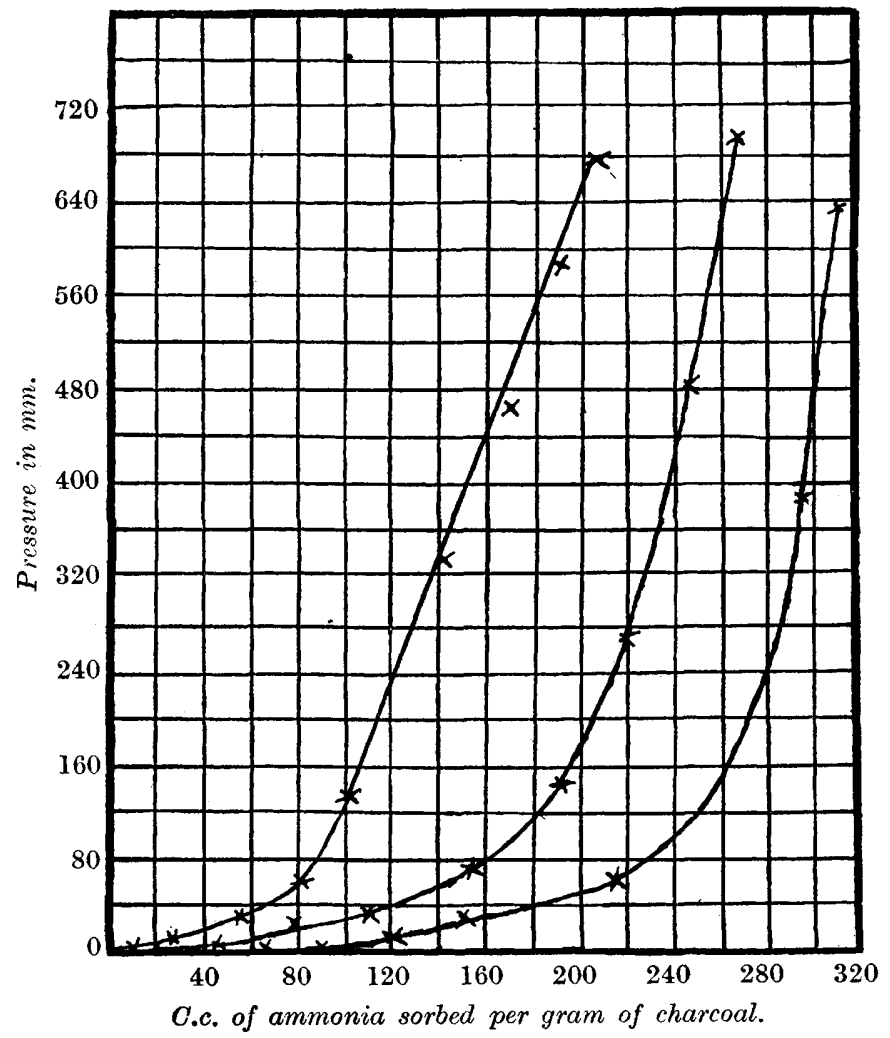

Determination of Equilibrium Pressures.

The equilibrium pressures at $18^{\circ}, 0^{\circ}$, and $-20^{\circ}$ were determined.

The carbon used in these experiments had D 1.825, and was obtained by heating the charcoal at about $900^{\circ}$ for forty-eight hours, being a portion of the sample used in series II above. Successive volumes of ammonia were admitted into the apparatus 
until equilibrium was established. The results are set out in the following table and are shown graphically in Fig. 1.

\begin{tabular}{|c|c|c|c|c|c|}
\hline \multicolumn{2}{|c|}{$18^{\circ}}$. & \multicolumn{2}{|c|}{$0^{\circ}$. } & \multicolumn{2}{|c|}{$-20^{\circ}$. } \\
\hline $\begin{array}{l}\text { C.c. of } \mathrm{NH}_{3} \\
\text { per gram }\end{array}$ & Pressure & $\begin{array}{l}\text { C.c. of } \mathrm{NH}_{3} \\
\text { per gram }\end{array}$ & Pressure & $\begin{array}{c}\text { C.c. of } \mathrm{NH}_{3} \\
\text { per gram }\end{array}$ & Pressure \\
\hline $\begin{array}{l}\text { harcoal. } \\
10 \cdot 5\end{array}$ & $\begin{array}{c}\text { in } \mathrm{mm} \text {. } \\
3 \cdot 8\end{array}$ & $\begin{array}{c}\text { of charcoal. } \\
21 \cdot 2\end{array}$ & $\begin{array}{c}\text { in } \mathrm{mm} . \\
2.8\end{array}$ & $35 \cdot 8$ & $\begin{array}{c}\text { in } \mathrm{mm} \text {. } \\
3 \cdot 1\end{array}$ \\
\hline $26 \cdot 2$ & $11 \cdot 5$ & $43 \cdot 6$ & $8 \cdot 7$ & $65 \cdot 3$ & $3 \cdot 5$ \\
\hline $56 \cdot 1$ & $29 \cdot 8$ & $79 \cdot 2$ & $24 \cdot 8$ & $91 \cdot 2$ & $5 \cdot 8$ \\
\hline $81 \cdot 1$ & $59 \cdot 2$ & $111 \cdot 5$ & $32 \cdot 6$ & $120 \cdot 6$ & $14 \cdot 5$ \\
\hline $102 \cdot 5$ & $131 \cdot 3$ & $153 \cdot 1$ & $75 \cdot 0$ & $150 \cdot 3$ & $29 \cdot 2$ \\
\hline $142 \cdot 3$ & 332.5 & $190^{\circ} 6$ & $134 \cdot 8$ & $214 \cdot 0$ & $60 \cdot 2$ \\
\hline $170 \cdot 2$ & $464 \cdot 2$ & $220 \cdot 2$ & $271 \cdot 0$ & $251 \cdot 3$ & $119 \cdot 8$ \\
\hline $191 \cdot 2$ & $586 \cdot 1$ & $244 \cdot 6$ & $482 \cdot 3$ & $293 \cdot 0$ & 388.8 \\
\hline $205 \cdot 2$ & $674 \cdot 8$ & $265 \cdot 1$ & $692 \cdot 3$ & $309 \cdot 0$ & $635^{\circ} 0$ \\
\hline
\end{tabular}

In the case of the isothermals at $0^{\circ}$ and $-20^{\circ}$, the lower portion of the curve indicates that a considerable increase in the volume of the gas sorbed makes only a small change in the equilibrium pressure, but after a certain point the conditions are reversed and a small change in the volume of the ammonia in the charcoal considerably increases the equilibrium pressure. This becomes more pronounced with lowering of temperature. The curves are very similar in character to those given by Travers (Proc. Roy. Soc., 1906, 78, 15) for carbon dioxide.

\section{Summary.}

Cocoa-nut charcoal carbonised at as low a temperature as possible and then heated at $600-900^{\circ}$ increases considerably in activity within certain limits.

The density is also increased by the same treatment.

When the charcoal has been strongly heated, the density increases, but the activity diminishes. This is due to the formation of a more compact form of carbon of higher density but of diminished sorptive capacity.

The equilibrium pressures at $18^{\circ}, 0^{\circ}$, and $-20^{\circ}$ have been recorded.

The Chemical Department,

University College, Nottingham. [Received, April 7th, 1921.] 